Goldschmidt 2021 Abstract

https://doi.org/10.7185/gold2021.8173

\section{No Oxygen, Less Diorite; No Biosphere, Smaller Continents} ERIC H CHRISTIANSEN ${ }^{1}$ AND BRADLEY W PITCHER ${ }^{2}$

${ }^{1}$ Brigham Young University

${ }^{2}$ Vanderbilt University

Presenting Author: eric_christiansen@byu.edu

The origin of Earth's distinctive felsic continental crust remains a fundamental problem. We have tested the hypothesis that the origin of low density, less subductible, dioritic continental crust may be linked to the rise of atmospheric oxygen, itself related to the evolution of the biosphere and the presence of liquid water on Earth's surface. To examine this idea, we have used Monte Carlo methods to complete a series of MELTS (Ghiorso et al., 1995) models of crystallization of basalt with varying water ( 0 to $6 \mathrm{wt} \%), \mathrm{fO}_{2}(-1$ to +3$)$, and $\mathrm{P}(100 \mathrm{MPa}$ to $500 \mathrm{MPa})$. Although both water and oxygen play important roles in the nature of the liquid line of descent, it is clear that fO2 plays a more important role than water in developing the calcalkaline differentiation trends found in many subduction related magmas. It is also clear that mafic magmas differentiating at high $\mathrm{fO}_{2}$ (e.g., QFM+2) produce felsic magma (here taken to be the dioritic bulk composition of Earth's continental crust) with less differentiation than low fO2 magmas (e.g., QFM)-largely because of the high- $\mathrm{T}$ fractionation of silica-poor magnetite in oxidized systems.

For example, at QFM+2 and $200 \mathrm{MPa}$, Augustine basalt differentiates to $63 \% \mathrm{SiO} 2$ with about $\sim 23 \%$ residual liquid, whereas only $1 \%$ liquid remains at $63 \% \mathrm{SiO}_{2}$ at $\mathrm{QFM}$. In other words, the production of high- $\mathrm{SiO}_{2}$, low density, less subductible continental crust is more efficient at high fO2 (regardless of water content). Thus, we suggest that as Earth's atmosphere became $\mathrm{O}_{2}$ rich through the evolution of the biosphere, the oceans were oxidized. As a result of ocean ridge metamorphism, the oceanic crust also became more oxidized. Upon subduction and dehydration of the altered oceanic crust, oxidized fluids were released into the overlying mantle wedge and induced partial melting. These oxidized melts fractionated to produce larger volumes of low density, crust-forming rock than before the Great Oxidation Event. In short, Campbell and Taylor's (1983) influential statement on the origin of continents--No Water, No Granite; No Oceans, No Continents-can be modified a bit: No Oxygen, Less Diorite; No Biosphere, Smaller Continents.

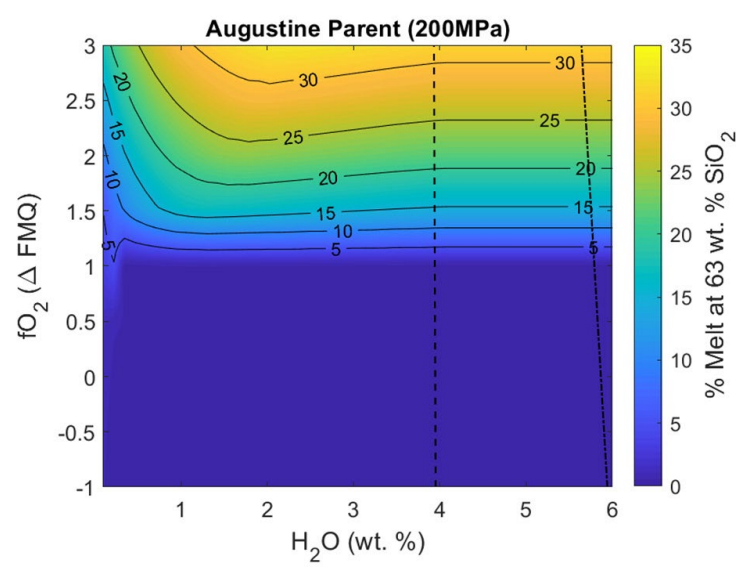

